\title{
PERFIL CONCEITUAL COMO TEMA DE PESQUISA E SUA APLICAÇ̃̃O EM CONTEÚDOS DE BIOLOGIA
}

\author{
Alexandre Cunha Vairo* \\ Luiz Augusto Coimbra de Rezende Filho**
}

RESUMO: Este trabalho traz um levantamento sobre como pesquisas têm trabalhado teórica e metodologicamente noções de perfil conceitual em Biologia. Em oito trabalhos selecionados, foram apreciados os aportes teóricos e as ferramentas usadas para coleta e análise dos dados. Foi observado que os autores utilizam tanto os referenciais teóricos e a metodologia propostos para o Modelo de Mudança do Perfil Conceitual, quanto referenciais complementares e métodos estatísticos, buscando avanços nas pesquisas. Nem todos os trabalhos conseguiram definir perfis conceituais para as noções estudadas, pois estas nem sempre atendiam todas as condições necessárias. A abordagem didática baseada nessa noção apontou contribuições para o enriquecimento dos perfis dos alunos e para a conscientização sobre a multidimensionalidade de um determinado conceito científico.

Palavras-chave: Perfil Conceitual. Educação. Produção Acadêmica

\section{CONCEPTUAL PROFILE AS A RESEARCH SUBJECT AND ITS APPLICATION IN TOPICS OF BIOLOGY}

ABSTRACT: This study conducted a survey on how researchers have been carrying on the theory and methodology of conceptual profiles assembly of Biology concepts. In eight selected works, an assessment of the theoretical framework and tools for collecting and analyzing data was made. It was observed that authors use the same theoretical and methodological framework proposed for the Conceptual Profile Approach, but they also use additional frameworks and statistical methods in data handling, aiming advances in research. Not all studies were able to define conceptual profiles for the addressed notions, because they did not always met all the necessary conditions. Teaching approaches based on this notion contributes to students' enrichment and awareness of the multi-dimensional character of a scientific concept.

Keywords: Conceptual Profile. Education. Scientific Production. 


\section{INTRODUCุÃO}

Muitos pesquisadores e educadores vêm direcionando esforços para identificar que perspectiva epistemológica melhor contribui para o processo de ensino-aprendizagem dos conceitos científicos. Algumas delas consideram o conhecimento escolar como algo pronto e estabelecido e que os alunos podem ser vistos como "tábulas rasas". Outras, como o construtivismo, partem do entendimento de que todo conhecimento deve ser construído ativamente pelos estudantes ao longo do processo educacional, e dão grande importância aos seus conhecimentos prévios.

O "paradigma construtivista" apresentou um fortalecimento a partir da década de 1970 devido às críticas aos modelos de ensino e aprendizagem positivistas. Assim, as estratégias de ensino passaram a tomar como ponto de partida as noções que os aprendizes já possuíam e tinham como objetivo oferecer possibilidades para os aprendizes construírem seus próprios conhecimentos (FREIRE, 1996).

De acordo com von Glasersfeld (1998) e Castañon (2005), Jean Piaget foi quem introduziu o termo "construtivismo" no século XX com o desenvolvimento de sua Epistemologia Genética. O construtivismo piagetiano é considerado pessoal, uma vez que sua busca está voltada para a análise do processo de evolução do conhecimento e da construção dos conceitos, realizada pelo indivíduo quando este interage com objetos do mundo. Assim, segundo essa perspectiva, seria de suma importância buscar entender como o aprendiz constrói seu conhecimento. Piaget considerava que o desenvolvimento intelectual do sujeito se dava por meio da adaptação da estrutura cognitiva aos novos conceitos, assim como se processa a adaptação dos seres vivos ao ambiente.

Todo o processo de construção do conhecimento abordado na teoria da reequilibração de Piaget analisa o que ocorre nas estruturas cognitivas do próprio sujeito, mas sem levar explicitamente em consideração a interação com outros sujeitos. Daí, na complementação da perspectiva construtivista, a contribuição do construtivismo sociocultural, cuja origem se encontra, segundo diversos autores, nos trabalhos de Lev Vygotsky.

Para Vygotsky, o desenvolvimento mental do indivíduo acontece no contato e na interação com outros indivíduos. Assim, esse autor deu maior destaque à prática do trabalho em grupo ou a momentos que criem oportunidades de troca de experiências e de conhecimentos entre aprendizes para a construção de conceitos e sua posterior internalização (VYGOTSKY, 1991). São esses constructos sócio-históricos e culturais que, por meio das interações sociais, provocam o desenvolvimento cognitivo do indivíduo. Essas interações são as responsáveis por gerar conflitos cognitivos que mobilizam as estruturas intelectuais do sujeito, reestruturando-as e contribuindo para o a formação de esquemas mentais e para o progresso intelectual.

Ao traçar um paralelo entre os dois grandes teóricos do desenvolvimento humano, enquanto Piaget apresenta uma ênfase na estruturação do próprio sujeito e atribui à maturação papel fundamental no desenvolvimento, Vygotsky destaca 
o aspecto interacionista, pois considera que na troca entre as pessoas é que se originam as funções mentais superiores.

A partir do momento em que foi estabelecido o construtivismo como paradigma, percebeu-se a importância do conhecimento que o aprendiz já possuía antes de ser introduzido ao conteúdo escolar formal, já que esse seria o ponto de partida para o trabalho com o conhecimento cientificamente aceito. Dentre uma série de modelos que surgiram, o Modelo de Mudança de Perfil Conceitual foi proposto inicialmente por Eduardo Mortimer como uma forma de modelar a heterogeneidade de pensamentos nas aulas de Ciências. Esse modelo entende que a construção de um conceito é um processo emergente, sempre produzido a partir de interações entre o indivíduo e experiências externas. Isso gera uma diversidade de conceituações, dispostas em um espectro crescente de complexidade de forma semelhante aos caminhos da construção do conhecimento ao longo da história, seguindo o modelo de perfil epistemológico proposto por Bachelard (1990) com relação às concepções sobre a realidade.

Essa noção bachelardiana indica que as concepções podem ser organizadas em zonas de características epistemológicas diferentes que fundamentam formas distintas de compreender a realidade. O progresso epistemológico implicaria no desenvolvimento e/ou surgimento de novas zonas que apresentem maior nível de complexidade, sem demandar que haja um completo abandono das outras concepções.

A proposta desse modelo, apesar de buscar entender as mudanças que ocorriam nos pensamentos dos indivíduos a partir do processo de ensino de conceitos científicos, apresenta algumas semelhanças com o perfil epistemológico, como a hierarquia entre as zonas, em que cada uma apresenta poder explanatório maior que a anterior, mas lhe adiciona dois novos elementos. O primeiro seria a distinção entre os compromissos epistemológicos e ontológicos de cada zona do conceito, uma vez que as dificuldades de alterar as características ontológicas são intimamente relacionadas aos problemas de aprendizagem em Ciências. O outro elemento é que as zonas não científicas não são abarcadas pelas escolas filosóficas e são fortemente influenciadas pelo contexto sociocultural. Daí a utilização, como base teórica, da noção de perfil epistemológico proposto por Barchelard, associado ao construtivismo sociocultural, com as ideias de Vygotsky.

Isso fez com que Mortimer (1995) definisse o perfil conceitual como um "sistema super-individual de formas de pensamento" que geram "modos de falar" empregados na enunciação de um conceito. Dessa forma, entende-se a evolução das ideias dos estudantes como a evolução de um perfil de concepções em que novas ideias adquiridas no processo de aprendizagem passam a conviver com as anteriores, admitindo a convivência entre o senso comum, o saber escolar e o saber científico e que a ausência de mudanças radicais não deve ser interpretada como fracasso (MORTIMER, 1996; AMARAL \& MORTIMER, 2004).

De acordo com Mortimer (1996), para a construção de um perfil conceitual é importante delimitar os compromissos epistemológicos e ontológicos que estruturam cada zona, para poder delimitá-las. Para isso, é preciso considerar uma 
grande diversidade de significados associados a um conceito e uma variedade de contextos nos quais eles podem ser inseridos. Daí se faz necessário investigar pelo menos três domínios responsáveis pela gênese de um conceito: domínio sociocultural, domínio ontogenético e domínio microgenético.

O levantamento da evolução histórica das ideias ou de um conceito daria conta do domínio sociocultural. Isso pode ser utilizado como um dos recursos para determinar tanto as zonas científicas quanto as pré-científicas, assim como para revelar seus compromissos epistemológicos e ontológicos. Adicionalmente, esse tipo de abordagem pode contribuir para investigar as ontodefinições de conceitos amplos e que só podem ser estruturados a partir de um paradigma científico.

Como o domínio ontogenético se refere às experiências pessoais do indivíduo, à sua história de desenvolvimento cognitivo, seus compromissos podem ser evidenciados a partir de trabalhos que abordem concepções alternativas de estudantes sobre o conceito de interesse e da coleta de dados empíricos por meio de questionários, entrevistas e gravações das interações discursivas nas situações de construção de significados (sala de aula, por exemplo). A coleta dos dados empíricos, além de permitir acesso ao domínio ontogenético, pode contribuir com a identificação do domínio microgenético, uma vez que tenta identificar a formação de conceitos individuais que ocorrem em escalas de tempo mais curtas, como no próprio processo de ensino-aprendizagem.

Apesar de normalmente envolver esse procedimento, a categorização do discurso escrito ou falado não costuma ser suficiente para permitir a delimitação das zonas de um perfil conceitual. Assim, as falas dos sujeitos devem ser interpretadas à luz desses compromissos relacionados aos seus contextos sociais. Isso também ocorre porque a forma de coleta e a interpretação dos dados ocorrem como parte de um processo dialógico estruturado pelas intenções e procedimentos do pesquisador.

A construção desse modelo ofereceu uma forma diferente de compreender o trabalho com conteúdos científicos nos ambientes de ensino, por entender que o aprendiz não tem a necessidade de abandonar suas concepções. Como consequência, é possível observar o uso do modelo em um grande número de publicações sobre variados conceitos ligados à educação em Ciências e a outras áreas do conhecimento, assim como diversas tentativas de se montar perfis de diferentes conceitos, tais como "Energia" (Física), "Transformação química" (Química), "Vida” (Biologia), "Harmonia” (Música), "Funções” (Matemática).

Uma forma de colaborar para uma visão panorâmica e crítica do conjunto de publicações sobre esse tema é desenvolver uma pesquisa de caráter bibliográfico. Essas pesquisas são denominadas normalmente de "estado da arte" ou "estado do conhecimento". Elas vêm contribuindo para divulgação e reflexão sobre diversos conhecimentos produzidos, além de permitirem que um determinado campo de conhecimento seja analisado dentro de um recorte de tempo, oferecendo, assim, a possibilidade de um ordenamento do conjunto de resultados e informações já obtidos nas pesquisas. Então, pode-se dizer que a principal contribuição desse tipo de pesquisa é deixar em evidência, de forma 
sintética, o conhecimento já produzido em uma área, apontando caminhos mais promissores para novos pesquisadores (FERREIRA, 2002).

O levantamento aqui realizado tem como objetivo responder a uma questão central: como as pesquisas têm utilizado a teoria e trabalhado metodologicamente a montagem de perfis conceituais? Além dessa questão, outras discussões complementares seriam: que características um conceito deve ter para que se possa montar um perfil conceitual dele? Como a noção de perfil conceitual vem sendo utilizada na pesquisa em temas relacionados à Biologia e ao seu ensino? Portanto, é possível dizer que o tema da presente pesquisa surgiu do interesse em compreender o estado de conhecimento sobre a noção de perfil conceitual. O trabalho tem a proposta de fornecer uma visão mais ampla do uso dessa noção em temas relacionados com Educação e Biologia para, assim, servir como ferramenta para construção de novos caminhos na pesquisa.

\section{MATERIAIS E MÉTODOS}

A pesquisa teve início com a realização de um levantamento documental das dissertações e teses disponibilizadas na Biblioteca Digital de Teses e Dissertações e no acervo, na internet, do Banco de Teses da CAPES/MEC. Dessa maneira, focalizamos pesquisas defendidas nos programas de pós-graduação credenciados pela CAPES que, por serem trabalhos mais extensos, permitem encontrar maior detalhamento da forma como foram conduzidos. Nas duas bases foi utilizado o termo "perfil conceitual" em qualquer parte do trabalho como modo de identificar diferentes formas de uso para essa noção, sem um recorte temporal delimitado. A última verificação nesses portais foi feita em agosto de 2011.

Como a busca foi feita em todas as partes dos trabalhos, foi necessário realizar uma análise prévia dos resultados para que fosse possível diagnosticar em que área do conhecimento o conceito foi utilizado. Após a classificação, buscou-se destacar a questão central de pesquisa do trabalho e demonstrar de que forma o referencial foi utilizado. Entretanto, como a busca bibliográfica realizada teve como enfoque apenas dissertações e teses, esse levantamento compõe um recorte restrito e, por consequência, pode limitar algumas conclusões obtidas.

\section{RESULTADOS}

Em acordo com os parâmetros descritos anteriormente, foram obtidas 24 dissertações e nove teses. Após uma leitura preliminar dos resumos das dissertações e teses encontradas, foram excluídos das análises os trabalhos que não tratavam diretamente de temas relacionados à Educação ou à Educação em Biologia (no Ensino Fundamental e Médio). Assim, o espaço amostral a ser analisado com maior aprofundamento passou a ser de seis dissertações e duas teses. 
Dos trabalhos selecionados, foram feitos breves resumos que permitissem ao leitor, em linhas gerais, entender como os autores trabalharam o tema "perfil conceitual" em suas obras. A apresentação dos trabalhos foi feita de acordo com o ano de publicação: em primeiro lugar as mais antigas. Nos resumos foram priorizados os objetivos da pesquisa e a forma como a noção de perfil conceitual foi utilizada.

$\mathrm{Na}$ dissertação de Oliveira (2005), "As concepcõos de biodiversidade: do professor-formador ao professor de Biologia em serviço", o autor buscou identificar os conceitos principais de biodiversidade dentro de uma perspectiva histórica e na literatura científica (no contexto da Biologia). Outro objetivo era investigar o perfil conceitual de biodiversidade de pesquisadores e professores.

Ele iniciou seu trabalho indicando a importância do estudo da biodiversidade e sua relação com a educação, uma vez que seus diversos significados tornam-se mais presentes na sociedade e o tema influencia aspectos econômicos, políticos, ecológicos e éticos patrimoniais, além da preocupação educacional. Assim, o tema é de grande valor social e científico, mas sua abordagem é feita de forma segmentada.

Para explicitar as noções de biodiversidade encontradas em diferentes contextos, o autor realizou uma revisão bibliográfica sobre biodiversidade e entrevistas semiestruturadas com os professores de diferentes níveis de ensino. O intuito era identificar as concepções presentes na literatura e nos sujeitos da pesquisa. Segundo o autor, o tema é polissêmico e dependente do contexto em que o indivíduo está inserido. Ele sugere que a noção de perfil conceitual pode ser uma boa ferramenta para auxiliar a compreensão dessa diversidade de concepções e indica que as entrevistas contribuíram para a tomada de consciência pelos sujeitos dos seus respectivos perfis.

A primeira tese a ser apresentada foi desenvolvida por Coutinho (2005), sob o título "Construção de Um Perfil Conceitual de Vida". Seu objetivo, como o próprio título indica, era determinar as zonas que compõem o perfil para o conceito de "vida".

A primeira etapa do trabalho foi realizar uma descrição histórica do conceito como forma de identificar os compromissos epistemológicos das zonas. Buscou-se identificar as concepções dos alunos de diferentes períodos de um curso de Biologia sobre o conceito, a partir de um questionário e uma entrevista baseada em situações-problema. Também foram realizadas entrevistas com estudantes de pós-graduação em ecologia e em genética.

Com base nos resultados identificados nos questionários e na bibliografia sobre o conceito de vida, o autor percebeu sete categorias do perfil desse conceito. Com o aprofundamento da pesquisa, essas categorias passaram e a ser consideradas zonas expandidas e, posteriormente, algumas delas foram agrupadas em três zonas reduzidas, que seriam as utilizadas no trabalho: externalismo, internalismo e relacional.

Os questionários permitiram a emergência dos perfis e a partir desses dados o autor elaborou o perfil conceitual característico dos alunos de cada período. Os resultados comprovaram a evolução dos conceitos ao longo do curso. Já as entrevistas ratificaram e permitiram maior aprofundamento da investigação das zonas já identificadas, além de apontar a existência de mais duas categorias, 
sendo consideradas eficientes, mas limitaram os contextos de uso das zonas. As entrevistas se mostraram um bom instrumento complementar ao fornecer aos participantes novos contextos e, consequentemente, a possibilidade da tomada de consciência e da emersão de novas zonas.

Na dissertação de Silva (2006), "O perfil conceitual de vida: ampliando as ferramentas metodológicas para sua investigação", o objetivo principal do trabalho era refinar a metodologia de obtenção de dados que foi utilizada na tese de Coutinho (2005). Dessa maneira, o questionário e os resultados desse último foram utilizados como norteadores.

Um novo questionário foi construído para a pesquisa e aplicado para alunos de graduação em Biologia e em Farmácia. Esse questionário diferenciava-se do utilizado em outras pesquisas por possuir um elevado número de questões e por todas elas serem discursivas. A partir daí o autor seguiu para a descrição das formas de categorização das respostas e da justificativa dos testes estatísticos utilizados para análise dos perfis. Isso é outra inovação da sua pesquisa, que utilizou escores brutos e escores produzidos por um programa que adota a Teoria de Resposta ao Item, e eles foram submetidos a análises de Clusters e ANOVA I e II.

Nas respostas do novo questionário foi possível perceber, entre os alunos, além da grande diversidade de concepções sobre o conceito de vida, muitas situações nas quais eles perceberam a heterogeneidade, as limitações e as lacunas de suas concepções, à medida que se deparavam com obstáculos causados pelas situações abordadas nas questões. As concepções foram, então, distribuídas nas diferentes zonas do perfil propostas por Coutinho (2005) (externalismo, internalismo e relacional). Além das zonas já identificadas, também foi possível a emersão de duas outras categorias não identificadas no trabalho de base, autonomia e sistema, que podem contemplar outros modos de expressão.

A dissertação de Gomes (2006), "Concepçôes cotidianas e científicas sobre competição na educação de jovens e adultos", tinha como objetivo principal compreender como as interações em sala de aula influenciavam a construção do conceito de competição. Para isso, ele propôs caracterizar e comparar as concepções dos alunos de uma turma antes, durante e após as aulas sobre Interações Ecológicas e, a partir daí, analisou como as interações contribuíram para a construção do conceito. Em seguida, selecionou quatro alunos para analisar com maior aprofundamento como se deu a elaboração conceitual durante uma sequência didática.

Como resultado da intervenção didática, o pesquisador percebeu que tanto a participação do professor quanto a interação entre os estudantes foram importantíssimas para a construção do conhecimento científico por parte dos alunos. Isso não se deu por uma mera substituição das ideias alternativas por científicas, e sim por uma extensão de suas concepções cotidianas, com a incorporação de concepções científicas. Mas, como esse não era um dos objetivos de seu trabalho, o autor não utilizou a noção de perfil conceitual de forma aprofundada. Ele apenas identificou a presença das zonas com diferentes graus de complexidade, mas não desenvolveu uma discussão sobre quais eram e em que contextos elas seriam aplicadas. 
A dissertação de Silva (2008), "Maré, mangue ou manguezal: um estudo de concepç̃es de estudantes no ensino fundamental", mostrou uma abordagem diferente ao buscar a identificação das concepções de crianças (entre sete e 11 anos) sobre o ecossistema do manguezal e quais dessas poderiam coexistir ao longo do processo de ensino-aprendizagem do conceito, por meio da observação de uma intervenção didática. Para isso, seriam utilizadas a noção de perfil conceitual e a teoria de Vygotsky sobre a formação de conceitos científicos.

A autora procurou descrever os elementos da formação de significados, explorar a importância do estudo das concepções alternativas na construção dos conceitos científicos e como essas devem ser abordadas na perspectiva da educação científica. Também buscou fundamentar o manguezal como um conceito a partir das dimensões históricas e epistemológicas. Dessa maneira, seria possível analisar o uso das concepções espontâneas sobre esse conceito, de acordo com cada contexto no discurso de sala de aula.

Para a realização da pesquisa, a autora buscou um desenho metodológico de caráter, prioritariamente, qualitativo, com características de uma observação participante. À medida que fazia o levantamento bibliográfico, ela também realizou um estudo piloto com outro grupo inserido no mesmo contexto sociocultural dos sujeitos de sua pesquisa, que consistia em entrevistar e pedir a produção de desenhos sobre o manguezal. A partir desses dados e de conversas com pesquisadores e professores da área, foi construída uma sequência didática.

A pesquisadora pôde perceber que ao longo da sequência didática houve uma evolução das concepções das crianças para uma linguagem mais científica. Ela também identificou que houve aproximação em alguns aspectos entre o discurso utilizado pelas crianças e a epistemologia dos conceitos de manguezal e ecossistema.

Segundo a autora, os resultados não foram considerados suficientes para serem utilizados na constituição de um perfil de manguezal. Mas ela sugere que este poderia ser feito a partir de um aprofundamento da epistemologia de ecossistemas e manguezais, a fim de verificar a possibilidade de enquadrar o manguezal como uma ontodefinição.

Já Viggiano (2008), em sua dissertação "Uma proposta de Levantamento de perfis conceituais de ensinar e aprender", apresentou como objetivo a construção de um instrumento metodológico que permitisse levantar os perfis conceituais de ensinar e de aprender de estudantes de um curso de Licenciatura em Física. Como forma de estabelecer uma primeira identificação de categorias que permitiriam a construção das zonas do perfil conceitual dos conceitos e seus contextos de utilização, o autor também fez um levantamento bibliográfico. Esse procedimento permitiu a elaboração de um esquema que serviu para a criação de questões delimitadoras de contexto. Além disso, foi possível identificar duas zonas (autoritária, dialógica) e uma categoria (amalgamada) que pode indicar uma outra zona que não pôde ainda ser assumida como tal.

Ele optou pela utilização de um questionário que permitia o aprofundamento adequado das respostas, sem a necessidade de entrevistas individuais. 
As respostas foram analisadas a partir de termos característicos de uma das três categorias estabelecidas. As respostas foram contabilizadas e foi utilizada estatística descritiva básica e teste de hipóteses para procurar relações entre as zonas de aprender e ensinar.

A última tese a ser apresenta foi desenvolvida pela pesquisadora Nicolli (2009), sob o título "Perfil conceitual de morte e a abordagem pedagógica do ciclo de vida, no ensino de ciências". A pesquisa teve como objetivos principais construir um perfil conceitual de morte e investigar como a abordagem pedagógica da temática "Ciclo de Vida" interferia nas zonas desse perfil.

Sua pesquisa teve início com um levantamento bibliográfico sobre a história do conceito de morte e sua conceituação em diferentes áreas do conhecimento, assim como em algumas culturas e sistemas religiosos. Adicionalmente, foram utilizados aportes teóricos de autores que apresentam conceituações de morte (e de vida) e são comumente abordados no meio acadêmico.

Para a coleta dos dados referentes aos perfis dos participantes, foi elaborado um questionário que expressava situações-problema. Elas foram construídas a partir da análise de dois trabalhos já apresentados anteriormente, que buscaram delimitar o perfil conceitual de vida: Coutinho (2005) e Silva (2006). O questionário foi aplicado a alunos da sétima série do Ensino Fundamental e a estudantes de diferentes períodos dos cursos de Biologia, Sociologia, Medicina e Pedagogia.

As análises teóricas permitiram a identificação de três categorias, que foram posteriormente consideradas zonas do perfil conceitual: naturalista, religiosa e relacional. Uma quarta categoria (Não respondeu/Não sabia) foi criada para agrupar as perguntas sem respostas ou com indicativo de desconhecimento e uma quinta (Outras) para reunir as que não se encaixavam em nenhuma das três zonas propostas.

Em seguida, foi realizada uma sistematização bruta dos dados, que consistia em tabular as respostas de cada sujeito para cada uma das questões, buscando seus respectivos "modos de pensar". Com essa forma de análise, foi possível perceber que quase todos os estudantes usavam apenas uma zona para expressar suas concepções.

A autora não obteve evidências de evolução de uma zona para outra ao longo dos períodos de um mesmo curso, confirmando suas expectativas iniciais de que não há uma abordagem pedagógica do conceito de morte satisfatória, tanto no contexto escolar quanto no acadêmico.

A última dissertação analisada foi a de Emerich (2010), com o título "Ensino de ciências: uma proposta para adequar o conbecimento ao cotidiano - enfoque sobre a água". Ela buscou investigar a relação entre as concepções prévias e o conhecimento científico sobre conceitos associados à água (como matéria, massa e energia), de alunos de duas turmas de $6^{\circ}$ ano do Ensino Fundamental.

A pesquisadora destaca que havia uma crença de acordo com a qual a utilização de experimentos empíricos permitiria que os alunos substituíssem as concepções alternativas pelas científicas, mas ao longo do processo ela não teria identificado a ocorrência de mudança conceitual. Ela destaca que apesar de a dinâmica adotada não contribuir para os alunos construírem novos conceitos 
científicos, ela ajudou a aproximar esses conceitos do cotidiano dos estudantes e foi possível perceber a evolução do perfil conceitual dos estudantes com ideias mais complexas do que no início da atividade. Apesar disso, não foi possível delimitar as zonas desse perfil.

\section{DISCUSSÃO}

O desenvolvimento da pesquisa buscou responder a questão central "como as pesquisas têm utilizado a teoria e trabalhado metodologicamente a montagem de perfis conceituais??' Para isso, foi feito o levantamento de teses e dissertações e a apreciação de como os autores se apropriavam da noção proposta por Mortimer e a utilizavam no processo dialógico com outros autores, assim como a forma de desenvolvimento da pesquisa para a construção de perfis conceituais.

Ao buscar a resposta para essa questão, percebemos que dentre os trabalhos, todos citam o referencial proposto por Mortimer e reconhecem sua importância para a pesquisa em Educação em Ciências. Entre as seis dissertações de mestrado selecionadas para uma análise mais aprofundada, apenas três conseguem identificar ou aprimorar o perfil conceitual de algum conceito científico (SILVA, 2006; SILVA, 2008; VIGGIANO, 2008). Já entre as teses, das duas selecionadas, ambas desenvolvem de forma bastante ampla o uso do referencial, e uma delas (COUTINHO, 2005) foi utilizada como ponto de partida para uma das dissertações (SILVA, 2006) e ainda foi citada em dois outros trabalhos analisados (NICOLLI, 2009 e VIGGIANO, 2008).

Além dos aportes que serviram de base para a composição do modelo (Bachelard e Vygotsky), fizeram parte dos trabalhos selecionados ideias de outros autores, que já apresentam papéis de destaque nas pesquisas sobre "perfil conceitual”, inclusive em parcerias com Mortimer, como: Amaral, Bizzo, Driver, El-Hani, Scott. Em adição a esses aportes, é possível encontrar importantes contribuições dos trabalhos de Bernstein, para a análise da construção do conhecimento escolar e do discurso pedagógico, a partir da noção de contexto (VIGGIANO, 2008), e Bakhtin como a noção de gêneros de discurso e linguagem social, pelo entendimento de que esses subsídios podem ajudar a relacionar as zonas do perfil conceitual aos diferentes modos de falar dos sujeitos (COUTINHO, 2005; NICOLLI, 2009; SILVA, 2006 e SILVA, 2008).

Nos trabalhos analisados, é possível perceber que os autores iniciam suas pesquisas com uma revisão bibliográfica sobre a construção do conceito na literatura científica, como forma de contemplar o domínio sociocultural, seguindo a orientação encontrada no trabalho de Mortimer (1996). A importância de se realizar uma revisão histórica do conceito fica bem clara na pesquisa de Coutinho (2005), na continuidade dela com Silva (2006) e na de Nicolli (2009), que produziram um capítulo de apresentação dos conceitos de interesse ao longo da história da ciência e, no caso dessa última, foi feita uma descrição do conceito de morte 
segundo a concepção de diversas religiões. Esse tipo de desenvolvimento, além de contemplar o domínio sociocultural, teve como objetivo investigar as ontodefinições para os conceitos de "vida" e "morte" que são considerados bastante amplos e só podem ser estruturados a partir de um paradigma científico. Também podemos destacar o trabalho de Silva (2008), que cumpriu essa etapa para delimitar o conceito de manguezal.

O segundo domínio que deve ser contemplado é o ontogenético. Para isso, é importante realizar uma investigação das concepções de aprendizes encontradas na literatura e a coleta de dados empíricos diretamente com os sujeitos da pesquisa. Como instrumento para coleta dos dados empíricos, podem ser utilizados questionários, entrevistas ou ainda, observação de situações de interações didáticas. O primeiro pode contribuir de forma bastante relevante para o aparecimento de significados ou categorias não previstas no levantamento bibliográfico, demonstrando concepções representativas dos processos ontogenéticos presentes na cultura na qual o sujeito está inserido e que podem ser utilizados para significar conceitos científicos.

Por sua vez, as entrevistas e as interações didáticas também apresentam importante potencial de contribuição para a pesquisa, podendo ir além da função do questionário, dando acesso ao domínio ontogenético e também ao microgenético, uma vez que auxiliam o sujeito na tomada consciência de seu perfil e permitem a identificação da gênese de um determinado conceito ao longo da interação.

Os resultados da coleta dos dados empíricos podem ser trabalhados de diferentes maneiras. Silva (2008), que utilizou como ferramenta para coleta de dados algumas interações discursivas, optou por realizar a análise das falas dos alunos para identificação das suas concepções. Já Viggiano (2008), que empregou um questionário, preferiu distribuir as respostas nas categorias previamente identificadas, para, assim, quantificar e identificar a forma de uso das zonas. Por sua vez, como pode ser observado nos trabalhos de Coutinho (2005), Silva (2006) e Nicolli (2009), que também usaram questionários em suas pesquisas, alguns métodos estatísticos foram empregados como forma de dar maior refinamento à análise dos dados.

Silva (2006) utilizou ferramentas da Teoria Clássica de Testes e da Teoria de Resposta ao Item (TRI) (BORTOLOTTI, 2003) como uma forma de complementar o trabalho de Coutinho (2005). Nesse último, além das análises quantitativas dos resultados, o autor também buscou examinar os perfis conceituais revelados pelas questões. Para isso, ele contabilizou o número de vezes que os respondentes utilizaram as categorias das zonas do perfil a partir de escores brutos. Mas, essa forma de análise gerou uma distorção por conta da quantidade de categorias presentes (zona relacional apresenta apenas uma categoria expandida, as outras duas, internalista e externalista, apresentam três cada). Para resolver esse problema, Silva (2006) utilizou, além dos escores brutos, a TRI para consolidar os dados e obter escores de expressão de zonas. Assim, ele atribuiu o valor $(0)$ caso o aluno não utilizasse determinada zona e valor (1) às respostas que apresentavam "modos de expressão" característicos de uma determinada zona, mesmo que o 
aluno utilizasse mais de uma categoria relacionada àquela mesma zona. Nicolli (2009) realizou procedimento semelhante ao de Coutinho (2005) para produzir escores brutos para o conceito de morte.

Além disso, como encontrado no trabalho de Silva (2006), uma forma de validar os dados obtidos está na aplicação de tratamentos estatísticos. Em seu trabalho, os escores encontrados foram submetidos à análise de clusters, o que permitiu pesquisar padrões de perfis mais comuns e sua frequência dentro da amostra. Também foram aplicados os testes estatísticos ANOVA I e II para realizar comparações mais consistentes entre grupos de dados, como por exemplo, se havia diferenças estatisticamente significantes na evolução das zonas entre os cursos (Biologia e Farmácia) e entre os diferentes períodos de cada um deles.

O uso dos artifícios listados anteriormente se faz necessário para o delineamento mais preciso das zonas do perfil conceitual, mas isso não torna a tarefa simples. Nem todos os autores conseguiram desenvolver uma abordagem com base na noção de perfil conceitual. Foi o que ocorreu com: biodiversidade (OLIVEIRA, 2005), competição (GOMES, 2006) e conceitos relacionados à água (EMERICH, 2010). Dentre outros fatores, que serão discutidos posteriormente, podemos destacar a complexidade em desenvolver uma pesquisa capaz de identificar os compromissos ontológicos e epistemológicos, que estabilizam formas de pensar um conceito, e de abordar os três domínios responsáveis pela gênese do perfil de um conceito científico.

Em seu trabalho, Oliveira (2005) tinha como um dos objetivos investigar o perfil conceitual de biodiversidade, mas não conseguiu realizar a construção dele. Ele identificou que apesar de haver uma definição geral para o termo, não há um consenso quanto à sua definição devido aos diversos contextos em que pode ser empregado. Por conta disso, apesar de ter seguido algumas etapas indicadas para delimitação das zonas (levantamento do histórico do conceito na literatura e entrevistas), não foi capaz de descrever o perfil desse conceito.

Já no trabalho de Gomes (2006), o autor não chega a propor a construção de um perfil conceitual e dá ênfase à teoria sócio-histórica de Vygotsky, mas tinha como um dos objetivos comparar as concepções de alunos e, em determinado momento, destaca o interesse em realizar uma avaliação sobre a evolução do perfil conceitual dos estudantes a partir dos dados de sua pesquisa. Ele realizou uma investigação de contextos na literatura nos quais os significados de "competição" poderiam ser utilizados (contemplando o domínio sociocultural), mas não usou essas informações de forma dialógica com os dados empíricos para estabelecer os compromissos epistemológicos e ontológicos do conceito. Assim, ele conseguiu identificar o domínio microgenético do conceito, mas sem dar conta do ontogenético.

Como no trabalho anterior, Emerich (2010) também não lançou como objetivo a produção de um perfil conceitual, mas pretendia que ao final da pesquisa houvesse dados suficientes para fazê-lo. Nesse trabalho isso não foi possível, apesar de a autora identificar que houve evolução no perfil. Ela utilizou conceitos relacionados a "água", como "matéria" e "massa", ou seja, não tinha apenas um conceito 
para buscar seus domínios genéticos, devendo procurar essas informações de cada um deles. Dessa maneira, não foi capaz de identificar categorias de análise a partir da revisão bibliográfica.

Outra questão relevante para esta pesquisa, "que características um conceito deve ter para que se possa montar um perfil conceitual dele?", não pode ser respondida com a análise dos trabalhos selecionados, já que eles não estabelecem com clareza que características seriam essas. O que se pode perceber é que esses conceitos devem ser amplos, devem possuir uma polissemia de significados e valores atribuídos a eles de acordo com o contexto no qual estão inseridos e devem apresentar relevância considerável numa determinada área de atuação. Isso faz com que seja possível encontrar pesquisas nas mais diversas áreas, não só Física, Química e Biologia, mas também Matemática, Epistemologia e Música, como foi evidenciado na busca.

Os conceitos trabalhados nas pesquisas atendem a todos os critérios citados acima. Mas, a questão da abrangência do conceito deve ser observada com bastante atenção. Os temas abordados nas pesquisas apresentam relevância para a Biologia e para a Educação, e podem ser considerados bastante gerais, mas justamente por isso Oliveira (2005) teve dificuldade em elaborar uma definição satisfatória para o conceito de "biodiversidade". Esse problema apareceu novamente nos conceitos de "vida" (COUTINHO, 2005; SILVA, 2006) e "morte" (NICOLLI, 2009), mas foi resolvido buscando-se, na descrição da história desses conceitos, ontodefinições que permitissem estruturá-los a partir de um paradigma científico.

Já para os conceitos de "competição" (GOMES, 2006) e "manguezal", (SILVA, 2008) não foi possível construir um perfil. No primeiro caso, é possível que tenha sido pelo fato de não ter sido proposto como objetivo, mas no segundo a autora destaca que identificou algumas convergências para possíveis zonas, mas deveria haver um aprofundamento em pesquisas posteriores para verificar se é possível enquadrar "manguezal" como uma ontodefinição. Isso porque provavelmente os conceitos de "manguezal", assim como o de "competição", não seriam amplos o bastante, fazendo parte de conceitos mais gerais como "ecossistema" e "relações ecológicas", respectivamente.

Sendo assim, a investigação do perfil de "manguezal" e de outros perfis de mesmo nível hierárquico, como "restinga", "cerrado" e outros, poderia produzir resultados específicos demais para cada um deles e, consequentemente, não permitiriam que as zonas de um perfil fossem consideradas em outros. Por isso, o ideal seria que no caso do "manguezal", ele, ou um dos outros conceitos de mesmo nível hierárquico, fosse o fio condutor para a investigação do perfil de "ecossistema". Assim como no caso da "competição", esse conceito ou um equivalente (como "predatismo" e "parasitismo") serviria como elemento condutor para a identificação do perfil de "relações ecológicas". Outra opção para desenvolver a pesquisa seria partir do conceito de maior amplitude ("ecossistema" ou "relações ecológicas”) para, em seguida, caso houvesse interesse, testar os resultados utilizando os conceitos mais particulares, como forma de validar as zonas eventualmente identificadas. 
No trabalho de Emerich (2010), não havia o objetivo de construir um perfil conceitual, e no título de seu trabalho constava "enfoque sobre água". Apesar disso, o objetivo era utilizar esse enfoque para trabalhar com conceitos como massa e densidade. Esses dois são passíveis de terem as zonas que os compõem analisadas. O mesmo não se pode afirmar para “água”. Seria, então, necessário, inicialmente, buscar se há uma definição própria para o conceito, ou se deveriam ser utilizadas ontodefinições.

\section{CONSIDERAÇÕES FINAIS}

Os dados revelam que as pesquisas utilizam a noção de perfil conceitual como referencial teórico para a compreensão de uma multiplicidade de concepções. Como a construção delas está relacionada às interações sociais, as teorias socioculturais de Vygotsky são utilizadas para investigações sobre o processo de aprendizagem. Já para a análise dos gêneros do discurso, presentes nas respostas dos participantes, encontramos forte presença da teoria da enunciação de Bakhtin.

Mas, para identificar as zonas do perfil de um conceito, algumas etapas devem ser cumpridas. A primeira delas é identificar se o conceito é passível de ter seu perfil delimitado. Para isso, ele deve atender a alguns requisitos como: ter relevância para uma determinada área curricular, possuir uma diversidade de significados dependentes de seu contexto de aplicação e ser amplo. Esse último critério requer maior atenção, pois alguns podem expressar de forma muito restrita zonas de um conceito mais abrangente. Outros conceitos possuem diferentes definições de acordo com o paradigma vigente em determinada época na história, então, devem ser estruturados por meio de ontodefinições.

Outra etapa a ser cumprida é a investigação dos três domínios genéticos dos conceitos, como forma de identificar os compromissos epistemológicos e ontológicos das zonas do perfil. O primeiro domínio a ser trabalhado é o sociocultural, a partir da realização de estudos históricos sobre as ideias científicas. O segundo é o domínio ontogenético, que pode ser contemplado a partir de um levantamento de dados da literatura sobre concepções alternativas de alunos e/ou com o uso de questionários ou entrevistas, para resgatar concepções representativas da construção do conhecimento do grupo pesquisado. Além disso, deve-se buscar acessar o domínio microgenético por meio de métodos, como entrevistas, e a partir da observação de atividades didáticas que permitam evidenciar a gênese de um conceito em um curto período.

Os dados obtidos com a investigação desses domínios têm servido para identificação das zonas e posterior categorização dos modos de pensamento dos sujeitos. Mas, os autores não têm se contentado em apenas categorizar essas concepções. É possível ver o emprego de análises estatísticas para estabelecer comparações refinadas entre sujeitos de diferentes níveis de ensino ou em momentos anteriores e posteriores a intervenções didáticas. 
Dessa maneira, além da presente pesquisa contribuir para novos trabalhos sobre o tema, indicando caminhos teóricos e metodológicos para a identificação de características e para a montagem de perfis conceituais, notamos que essa abordagem se constitui como um importante referencial sobre a aprendizagem de conceitos científicos. Isso porque os problemas de aprendizagem estão relacionados à dificuldade de se alterar as características ontológicas de um conceito. Assim, o uso desse referencial pode contribuir para uma prática que apresente conceitos científicos de forma mais eficiente, uma vez que, de acordo com esse modelo, o processo de ensino-aprendizagem deve ter dois objetivos: o primeiro é o enriquecimento do perfil conceitual dos indivíduos; o outro é apresentar a eles a multiplicidade de modos de pensamentos que formam um perfil e os contextos em que cada um pode ser aplicado. Essa forma de o modelo conceber a aprendizagem norteou os trabalhos selecionados e, em maior ou menor grau, os seus autores reconheceram essa evolução e a tomada de consciência que os estudantes tiveram do seu perfil, mesmo nas pesquisas que não conseguiram delimitar as zonas para o perfil do conceito com que trabalharam.

\section{REFERÊNCIAS BIBLIOGRÁFICAS}

ALVES, G. S. O uso de softwares de Geometria Dinâmica para o desenvolvimento de habilidades cognitivas: uma aplicação em alunos do ensino médio. 2004. 270 f. - Dissertação (Mestrado Em Informática) Núcleo de Computação Eletrônica, Universidade Federal do Rio de Janeiro. Rio de Janeiro, 2004.

AMARAL, E. M. R.; MORTIMER, E. F. Un perfil conceptual para entropía y espontaneidad: una caracterización de las formas de pensar y hablar en el aula de Química. Educación Química, v. 15, n. 03, p. 01-75, 2004.

BACHELARD, G. Materialismo Racional. Trad. Arthur Lopes Cardoso. Lisboa: Edições 70, 1990.

BORTOLOTTI, S. L. V. Aplicação de modelo de desdobramento graduado generalizado da Teoria da Resposta ao Item - TRI. 2003. 107f. Dissertação (Mestrado em Engenharia de Produção) - Programa de pós-graduação em Engenharia de Produção, Universidade Federal de Santa Catarina, Santa Catarina, 2003.

CASTAÑON, G. A. Construtivismo e ciências humanas. Ciência \& Cognição, Rio de Janeiro, v. 2, n. 5, p. 36-49, 2005.

CASTAÑON, G. A. Construtivismo social: a ciência sem sujeito e sem mundo. 2009. 229 f. Dissertação (Mestrado em Filosofia (Lógica e Metafísica)) - Instituto de Filosofia e Ciências Humanas, Universidade Federal do Rio de Janeiro, Rio de Janeiro, 2009.

COUTINHO, F. A. Construção de um perfil conceitual de vida. 2005. 181 f. Tese (Doutorado em Educação) - Faculdade de Educação, Universidade Federal de Minas Gerais, Belo Horizonte, 2005.

EMERICH, C. M. Ensino de ciências: uma proposta para adequar o conhecimento ao cotidiano enfoque sobre a água. 2010. 98 f. Dissertação (Mestrado Em Educação em Ciências) - Instituto de Ciências Básicas e da Saúde, Universidade Federal do Rio Grande do Sul, Porto Alegre, 2010.

FERREIRA, N. S. A. As pesquisas denominadas "Estado da Arte". Educação \& Sociedade. N. 79, p. 257-272, 2002.

FREIRE, P. Pedagogia da Autonomia: saberes necessários à prática educativa. São Paulo: Paz e Terra, 1996.

GOMES, J. R. J. Concepşões cotidianas e científicas sobre competição na educação de jovens e adultos. $2006.140 \mathrm{f}$. Dissertação (Mestrado em Educação em Ciências e Matemáticas) - Núcleo Pedagógico de Apoio ao Desenvolvimento Científico, Universidade Federal do Pará, Belém, 2006. 
KARAM, R. A. S. Relatividade restrita no início do ensino médio: elaboração e análise de uma proposta. 2005. 244 f. Dissertação (Mestrado em Educação) - Curso de Mestrado em Educação Científica e Tecnológica, Universidade Federal de Santa Catarina, Florianópolis, 2005.

MORTIMER, E.F. Evolução do atomismo em sala de aula: mudança de perfis conceituais. 1994. $292 \mathrm{f}$. Tese (Doutorado em Educação) - Faculdade de Educação, Universidade de São Paulo, São Paulo, 1994. 265-287, 1995. Conceptual change or conceptual profile change? Science \& Education, v. 4, n. 3, p. Construtivismo, mudança conceitual e o ensino de ciências: para onde vamos? Investigações em Ensino de Ciências, v. 1, p. 20-39, 1996. . Linguagem e Formação de Conceitos no Ensino de Ciências. Belo Horizonte: Editora UFMG. 2000.

NARDI, R.; GATTI, S. R. T. Uma revisão sobre as investigações construtivistas nas últimas décadas: concepções espontâneas, mudança conceitual e ensino de ciências. Ensaio Pesquisa em Educação em Ciências, Belo Horizonte, v. 6, n. 2, 2004.

NICOLLI, A. A. Perfil conceitual de morte e abordagem pedagógica do ciclo de vida, no ensino de ciências. 2009. 236 f. Tese (Doutorado em Educação) - Faculdade de Educação, Universidade Federal de Minas Gerais, Belo Horizonte, 2009.

OLIVEIRA, L. B. Operfil conceitual de biodiversidade: do professor-formador ao professor de biologia em serviço. 2005. 282 f. Dissertação (Mestrado em Educação) - Faculdade de Educação, Universidade da São Paulo, São Paulo, 2005.

SILVA, F. A. R. Operfil conceitual de vida: ampliando as ferramentas metodológicas para sua investigação. 2006. 161 f. Dissertação (Mestrado em Programa de Pós-Graduação em Educação) - Faculdade de Educação, Universidade Federal de Minas Gerais, Belo Horizonte, 2006.

SILVA, K. M. E. Maré, mangue ou manguezal: um estudo de concepções de estudantes no ensino fundamental. 2008. 161 f. Dissertação (Mestrado em Ensino das Ciências) - Programa de Pósgraduação em Ensino das Ciências, Universidade Federal Rural de Pernambuco, Recife, 2008.

VIGGIANO, E. Uma proposta de levantamento de perfis conceituais de ensinar e aprender. 2008. $250 \mathrm{f}$. Dissertação (Mestrado em Ensino de Ciências) - Faculdade de Educação, Instituto de Física, Instituto de Química e Instituto de Biociências, Universidade de São Paulo, São Paulo, 2008.

VYGOTSKY, L. S. A formação social da mente. São Paulo: Martins Fontes, 1991. 191p.

VON GLASERSFELD, E. Construtivismo: Aspectos Introdutórios. In: FOSNOT, C. (Org.) Construtivismo: Teorias, Perspectivas e Prática Pedagógica. Porto Alegre: Artmed, 1998. p. 19-23. 